\title{
LA GESTIÓN EDUCATIVA MIRADA DESDE OTRAS EXPERIENCIAS
}

Mag. Liliana Jabif *

Voy a utilizar este espacio para comentar algunos aspectos de las múltiples acepciones que encierra el término de gestión educativa a partir de una experiencia que viví en Suecia mientras realizaba estudios en la Universidad de Lund y trabajaba en el sistema educativo del mencionado municipio.

Quisiera compartir uno de los ejes de problemas que caracterizan la situación de la educación en América Latina en general, del cual no escapa nuestro país, y que está vinculado con aspectos de gestión educativa. Me voy a referir a lo que tantas veces ha mencionado Tedesco ${ }^{1}$ : la escasa permeabilidad a la innovación y a la apertura que presentan los sistemas educativos de los países de la región, frente a la necesidad de desarrollar los cambios que exige un mundo altamente tecnificado y globalizado, en donde la renovación de las ideas y de las prácticas de dirección deberían constituir claves estratégicas.

Al reflexionar sobre las variables que desde el punto de vista de la gestión estarían incidiendo en este fenómeno, emergen en nuestros países algunas patologías y desviaciones que varios investigadores ${ }^{2}$ han abordado en estudios sobre la región, y cuyos signos más evidentes son la burocratización, la lentitud de los procesos, la falta de visión de futuro, la escasa construcción de redes.

Estos, que constituyen sólo algunos de los problemas típicos, se relacionan con ciertas prácticas tales como: procesos de toma de decisiones sobre bases no objetivas (hay diagnósticos, hay información pero, ¿se los utiliza realmente para anticipar los problemas y generar soluciones?); escaso trabajo en redes y en equipos (¿hasta qué punto se potencia la articulación y la complementariedad de las estructuras?); falta de comunicación con el interior de las instituciones (¿se generan los espacios para que las ideas se concreten y trasladen a las formas de trabajar?), lo que pondría en evidencia ciertos criterios del management dominante que afectan la eficiencia de la gestión del sistema educativo para el logro de la calidad de los aprendizajes.

La experiencia de haber participado del debate pedagógico de fines de los años 70 en los países nórdicos, especialmente en Suecia, país donde realicé mis estudios de grado y postgrado en educación y donde tuve la oportunidad de colaborar en proyectos de innovación cuyo punto de partida fueron los estudios prospectivos y de escenarios futuros, me permitió vivenciar y analizar una gestión educativa que opera con una lógica basada en la anticipación.

La prospectiva, que a decir de Godet ${ }^{3}$ es "un panorama de los futuros posibles de un sistema destinado a clarificar las consecuencias de las acciones encaradas", ha sido utilizada con mucho vigor en todos los campos, sobre todo por el dinamismo de los cambios y la incertidumbre que los acompañan.

En el campo de la educación, es clásico el estudio de Lesourne ${ }^{4}$ quien preparó el futuro del sistema educacional francés, señalando las cuestiones claves para la reforma educativa en ese país. También, diversas agencias del sistema de Naciones Unidas como PNUD y UNESCO, han generado estudios de esa naturaleza, realizando varias investigaciones de tendencias a largo plazo. Así, la finalidad de la prospectiva es ampliar la reflexión sobre las decisiones de hoy que pueden afectar el futuro. Como el futuro no es considerado una prolongación del pasado y del presente, los estudios prospectivos pretenden otorgar una mayor visibilidad a la toma de decisiones. 
Hecha esta apreciación, y a los efectos de ilustrar mejor la idea que motiva esta charla, comentaré una experiencia que tuvo lugar en la municipalidad de Lund, Suecia, durante los años 1978-1985 y de la cual formé parte.

Los estudios sobre las variables de entorno -entre otras el referido al crecimiento demográfico de niños extranjeros debido a la política de inmigración-, condujeron al debate sobre la importancia de la enseñanza del idioma materno en la escuela a los efectos de mejorar los resultados de aprendizaje.

Los resultados del análisis prospectivo, originados en estudios comparativos sobre bilingüismo, efectos conflictivos de la multiculturalidad en EEUU y Canadá, y análisis económicos de costo beneficio, entre otros, condujeron a las autoridades del Ministerio de Educación a plantear el problema a las autoridades locales. Los gestores educativos de los municipios cuya proporción de inmigrantes aumentaría considerablemente en los próximos años, tomaron una decisión innovadora: la incorporación de la enseñanza del idioma materno en la currícula y de una nueva figura, el maestro o profesor de idioma materno para planificar, organizar y ejecutar el acto educativo en forma conjunta con el docente regular ${ }^{5}$.

En este proceso, la gestión y la administración fueron ejes del sistema que iniciaron un proceso de "reingeniería" a los efectos de viabilizar la reforma en su conjunto y lograr mayor eficacia en los resultados.

\section{La puesta en marcha de las experiencias piloto}

Para la elección de los municipios en donde se iniciaría la reforma como experiencia piloto, se utilizaron diferentes fuentes de información objetiva: el sistema educativo sueco (cobertura, calidad de los aprendizajes, etc.), los sistemas educativos y experiencias en EEUU y Canadá, las necesidades actuales y futuras del mundo del trabajo y del empleo, las culturas, situación social, económica y política de los países de los inmigrantes, entre otras. De esta forma el análisis prospectivo indicó cuáles serían los municipios, y dentro de éstos las escuelas más vulnerables a los impactos de la política de inmigración.

Los gestores participantes, diseñaron una estrategia de "marketing" de la reforma, dirigida a los diferentes actores involucrados: docentes, padres, alumnos y sociedad en general, con el objetivo de comunicar, sensibilizar, involucrar y crear una actitud positiva hacia el cambio.

Hacia la sociedad en general se difundieron las investigaciones y los estudios temáticos y de opinión que la Universidad de Lund había realizado, a través de los medios masivos de comunicación. Para los docentes, quienes recibieron los informes de investigación y las necesidades planteadas por el Ministerio de Educación, se organizaron talleres sobre estudios de caminos críticos, gráficos de árbol de problemas, reflexión sobre la acción, y se elaboraron propuestas para la implementación de la innovación. Se crearon equipos de trabajo entre docentes de lengua materna y docentes regulares para trabajar sobre la dimensión relacional, con el fin de poner en práctica los valores de cooperación, consulta y formación continua. Para propiciar la construcción de redes de coordinación y comunicación profesional, se crearon espacios y tiempos específicos, destinados a la reflexión sobre la práctica y a la determinación de objetivos compartidos.

De esta forma, las estrategias apuntaron a fortalecer a los centros educativos que participaron de las experiencias piloto, los cuales se constituyeron en espacios propicios para la construcción de una visión compartida, de clarificación de metas y objetivos, de generación de consensos y de generación de aprendizajes sinérgicos.

\section{La generalización de la propuesta}

Los estudios realizados a los dos años de la puesta en marcha de las experiencias piloto ${ }^{6}$, permitieron extraer algunas conclusiones relevantes para la expansión de la propuesta. El resumen no exhaustivo de los principales aspectos que fueron considerados sigue a continuación: 
- Los centros educativos serían las unidades clave de organización. Debido a que la magnitud, intensidad y configuración de los problemas sería específica para cada escuela o barrio, éstos deberían adecuar las metodologías de enseñanza aprendizaje y los sistemas de medición de la calidad según la complejidad de sus realidades locales.

- Se reorganizaría el trabajo a partir de la creación de equipos en donde docentes regulares, docentes de idioma materno, dirección y personal de apoyo (fonoaudiólogos, psicólogos, enfermeros) tendrían tiempos y espacios específicos para planificar, identificar problemas, e intercambiar experiencias.

- Se generarían espacios para la capacitación permanente de los docentes incluyéndose la formación en valores, especialmente aquellos que sustentarían el proyecto: la integración, la diversidad, la apertura, la colaboración.

- Los gestores deberían crear una visión compartida, analizando el "dónde estamos", "adónde queremos ir" y "cuáles son las concepciones y principios educativos que queremos promover" con todo el personal afectado al centro educativo y con los padres de alumnos.

\section{Conclusiones}

- Los análisis prospectivos sirvieron de base para el inicio de una innovación educativa en aquellos municipios que recibirían en los próximos años un alto porcentaje de extranjeros como consecuencia de la política de inmigración. La evaluación de la experiencia realizada por la Universidad de Lund indicó, entre otros resultados, "el rol fundamental que desempeñó el conjunto de estudios anticipatorios integrados para el diseño de las estrategias de implementación de la reforma"7.

- Los altos niveles de autonomía otorgados a las escuelas para que definieran los procedimientos y las estrategias pedagógicas más pertinentes para el logro de los objetivos, exigieron como condición necesaria un alto nivel de profesionalidad de los docentes. Tanto desde el punto de vista pedagógico en sentido estricto como desde la organización institucional, el docente jugó un rol central en las transformaciones. Entre las numerosas consecuencias que produjo la mayor autonomía escolar sobre el desempeño docente, fue la exigencia del trabajo en equipo (la unidad de trabajo dejó de ser sólo el salón de clase para ser la escuela) y el fortalecimiento de su capacidad de evaluación de resultados.

- El estilo de liderazgo participativo, utilizado por los gestores durante el proceso de implantación de la innovación, permitió construir las redes comunicacionales que se caracterizaron por la doble vía, no sólo de emisión sino también de escucha, atenta a las demandas, ideas y propuestas para concretar una visión de futuro consensuada y compartida. Así se analizaron factores críticos, fortalezas y debilidades del centro para generar aprendizajes significativos, oportunidades y amenazas para construir el nuevo escenario y encontrar patrones de funcionamiento, pensar sobre qué debía permanecer y que debía cambiar.

- Los tiempos y espacios asignados al centro para la formación de todos los actores en nuevas competencias y especialmente en los aspectos vinculados con los valores necesarios para que -por medio de la innovación- se pudieran obtener aprendizajes múltiples y significativos en los alumnos y docentes, así como también contribuir a la construcción de una sociedad de consenso y no de conflicto. 


\section{Qué lecciones podemos aprender}

He comentado esta experiencia con la finalidad de que pudiera servir de disparador de interrogantes, tanto como para permitirnos reflexionar en voz alta sobre la importancia de una gestión educativa que no "aplaste"el cambio sino que lo facilite. En este sentido cabe preguntarse: ¿Cómo desarrollar gestores estratégicos con espíritu de prospectiva y que al decir de Senge ${ }^{8}$, "sepan qué debe suceder?" ¿Cuáles son las competencias que éstos deberán desarrollar para alentar a las organizaciones educativas al cambio, generar proyectos compartidos, redes de alianzas, liderar actores, fomentar la integración, aprovechar la diversidad? ¿Qué tanto deben comprender sobre los procesos por los cuales las diferentes partes de la realidad se interconectan y dependen recíprocamente?

El desafío a que fueron confrontados los gestores suecos fue al de abrir el centro educativo al aprendizaje, a que docentes de diferentes culturas e identidades encararan y resolvieran sistemáticamente problemas, generaran nuevas aproximaciones y experimentaciones, aprendieran a partir de la propia experiencia y de la de otros, originando conocimiento y trasladándolo a sus prácticas.

Si esto se logró fue gracias a la renovación de las prácticas de gestión del sistema educativo, el rediseño del trabajo educativo bajo los principios del fortalecimiento de la cooperación profesional a todo nivel, la integración de funciones antes separadas como el diseño y la ejecución, la reorganización de la comunicación a partir de redes y sobre todo, a la creación de una gestión flexible que supo aplicar estrategias diversas para promover soluciones específicas a problemas complejos, con creatividad.

Sin embargo, el gran principio articulador e integrador de la experiencia, fue el paradigma de la colaboración que permitió reunir los conocimientos y capacidades del profesorado, responder mejor a las limitaciones del entorno, mejorar la calidad del aprendizaje, fortalecer la confianza entre todos los actores y ayudar a que éstos superaran los fracasos y frustraciones que acompañaron los cambios en sus primeras etapas.

Finalmente, deseo agregar que esta transformación se logró también porque hubo líderes capaces de crear la motivación de que el camino era no sólo deseable sino posible, y seguidores que se revalorizaron en su rol al entender que, como señala Rifkin" en su libro "El fin del trabajo", cuando ya las máquinas hayan sustituido al hombre en las industrias, no habrá tecnología que pueda sustituirlo en aquellos trabajos en donde los seres humanos deban trabajar con otros seres humanos, como en la educación. 


\section{Notas:}

${ }^{1}$ Tedesco J. 1995. EI nuevo pacto educativo. Educación, competitividad y Ciudadanía en la sociedad moderna. Madrid: Anaya.

${ }^{2}$ Navarro J, et al. 2000. En perspectivas sobre la Reforma Educativa.USAID, BID: Instituto Harvard para el Desarrollo Internacional.

${ }^{3}$ Godet M. 1997. De l 'anticipation al 'action. En Manual de Prospective Stratégique 1. Paris: Dunod.

${ }^{4}$ Lesourne J. 1993. Educación y Sociedad, los desafíos del año 2000. Barcelona: Gedisa.

${ }^{5}$ Paulston, PG. 1985. Educational change in Sweden. Pedagogiska Institutionen: Lunds Universitet.

${ }^{6}$ Marklund et al. 1986. Fran reform till reform. Pedagogiska Institutionen: Lunds Universitet.

${ }^{7}$ Marklund et al. op cit. en nota (6).

${ }^{8}$ Senge, P. 1995. La Quinta Disciplina en la práctica. Barcelona: Granica.

${ }^{9}$ Rifkin J. 1996. El fin del trabajo. New York: PUTMAN'S SONS.

* Magister en Educación. Consultora en Gestión Educativa. 